OPEN ACCESS

Edited by:

Kevin Lu,

University of South Carolina,

United States

Reviewed by:

Nan Huo,

Mayo Clinic, United States

Junjie Ma,

Amgen, United States

${ }^{*}$ Correspondence:

Bing Han

hbshcn@fudan.edu.cn

Jing Yuan

jyuan@fudan.edu.cn

†These authors share first authorship

Specialty section

This article was submitted to Family Medicine and Primary Care,

a section of the journal

Frontiers in Medicine

Received: 07 January 2021

Accepted: 03 February 2021

Published: 01 March 2021

Citation:

Yuan J, Shen C, Wang C, Shen G and

Han B (2021) Assessment of Physician's Knowledge of Potential Drug-Drug Interactions: An Online Survey in China.

Front. Med. 8:650369. doi: 10.3389/fmed.2021.650369

\section{Assessment of Physician's Knowledge of Potential Drug-Drug Interactions: An Online Survey in China}

\author{
Jing Yuan ${ }^{1 *}$, Chunying Shen ${ }^{1 \dagger}$, Chengnan Wang ${ }^{1}$, Gang Shen ${ }^{2}$ and Bing Han ${ }^{1 *}$ \\ ${ }^{1}$ Minhang Hospital \& Department of Clinical Pharmacy at School of Pharmacy, Fudan University, Shanghai, China, \\ ${ }^{2}$ Department of Neurosurgery, Minhang District Central Hospital, Shanghai, China
}

Background: Drug interactions are the most common preventable cause of adverse drug reaction, which may result in drug toxicity or undesired therapeutic effect with harmful outcomes to patients. Given the rising use of combination therapies, the main objectives of this study were to estimate the degree to which physicians can identify potential drug-drug interactions (PDDIs) correctly and to describe the common source of information used by physicians when they need to check PDDls.

Methods: A cross-sectional survey utilizing a self-administered online questionnaire was conducted among physicians in China. Participants were asked to classify 20 drug pairs as "no interaction," "may be used together with monitoring," "contraindication," and "not sure." We also collected data on the physician's source of information and altitude toward the PDDls. An ordinary least square regression model was performed to investigate the potential predictors of PDDI knowledge.

Results: Eligible questionnaires were obtained from 618 physicians. The respondents classified correctly 6.7 out of 20 drug pairs, or $33.4 \%$ of the drug interactions investigated. The number of drug pairs recognized by respondents was ranged from 0 to 16 . The percentage of physicians who recognized specific drug pairs ranged from $8.3 \%$ for no interactions between conjugated estrogens and raloxifene, to $64.0 \%$ for the interaction between dopamine and phenytoin. When the respondents want to check PDDI information, the most commonly used source of information was package inserts ( $n=572,92.6 \%$ ), followed by the Internet or mobile Apps ( $n=424,68.6 \%$ ), consultation with clinical pharmacists $(n=384,62.1 \%)$, medical textbooks ( $n=374$, $60.5 \%)$, knowledge base in Chinese ( $n=283,45.8 \%$ ), and other physicians ( $n=366$, $59.2 \%)$. In the multiple regression analysis, the significant predictors of a higher number of recognized drug pairs were years of practice and altitudes toward PDDIs.

Conclusion: In this online survey accessing physician's ability to detect PDDIs, less than half of the drug pairs were recognized, indicating unsatisfactory level of knowledge about the clinically significant drug interactions. Continuing education and accessible electronic database can help physicians detecting PDDls and improve drug safety.

Keywords: drug-drug interaction, PDDI, adverse drug event, survey, knowledge, medication 


\section{INTRODUCTION}

A drug-drug interaction occurs when the pharmacokinetic or pharmacodynamic properties of a drug are altered when two or more drugs are taken simultaneously $(1,2)$. The interactions between two or more drugs may exist antagonistic or synergistic effect, both of which lead to drug toxicity or undesired therapeutic effect with harmful outcomes to patients (3-5). The potential drug-drug interactions (PDDIs) were identified in around $30 \%$ of the prescriptions in the outpatient (6) and oncology departments in China $(6,7)$. Even though the prevalence data is largely lacking in China, the PDDIs may be more prevalent in intensive care settings (8) and hematology (9, 10 ), based on the data from other countries. Patients experienced a PDDI are generally associated with a longer hospital stay (11) and higher medical costs $(12,13)$, leading to substantial financial burden on healthcare systems as well as on patients and society (14).

Physicians play a key role in preventing and reducing the risk of PDDIs and associated adverse outcomes. Unlike other countries such as the United States (U.S.), the clinical decision support system, which assists clinicians to detect PDDIs, is not commonly available in China. Physicians rely on their own knowledge to recognize PDDIs when writing a prescription. Even with the help of clinical decision support system, the performance of such system in terms of accurately identifying PDDIs was still unknown in China. Unsatisfactory performance of these systems has been reported in U.S $(15,16)$. For example, large variations in the electronic databases were reported (17-20), resulting in confusions among clinicians. In a recent study comparing three commercial knowledge databases - First DataBank (FDB), Micromedex, and Multum, it was found that the overlap of drug pairs in all these three knowledge bases was as low as $5 \%$, and the number of alerts generated for serious PDDIs were ranged from 25 to 145 alerts per 1,000 prescriptions (18). Despite the suboptimal performance of computerized systems, clinicians tend to override the automated alerts and may ignore PDDIs (21).

To our best knowledge, however, no studies have attempted to test physician's knowledge of PDDIs in China. Internationally, few studies assessed the ability of clinicians to detect PDDIs and their sources of drug information (22-25). In a postal survey of U.S. prescribers, response from a 16-item questionnaire suggested that prescribers were able to detect $42.7 \%$ of drug combinations (22). In another survey using simulated prescription profiles, $67 \%$ of 2-drug combinations were categorized correctly by pharmacists (23). In addition to the PDDI knowledge, the source of information contributes to the irrational use of medicines. For example, if physicians rely on the drug information from pharmaceutical companies rather than evidence-based guidelines, incorrect medication use may occur (26). But limited data is available for where the physicians obtained their PDDI information in China.

China has become the second largest pharmaceutical market in the world. With the rising use of medications, it is becoming increasingly urgent to navigate potential ways reducing the risk of PDDIs. In 2019, the National Health Commission (NHC) released opinions on strengthening rational use of medicines to address the emerging issue in patient safety. As such, understanding the physician's knowledge level of PDDIs is warranted to develop evidence-based strategies and policies to improve patient care. Therefore, the objective of this study was 3-fold: [1] to estimate the degree to which physicians can identify PDDIs correctly; [2] to describe the source of information that physicians used; [3] to understand their altitude with respect to improving knowledge level of PDDIs.

\section{MATERIALS AND METHODS}

\section{Study Design}

This study employed a cross-sectional study design. We carried out an anonymous, online survey that was open to practicing physicians in Shanghai, China, from November 1 to December 15,2020 . This study was approved by the Institutional Review Boards of Minhang Hospital of Fudan University. The study protocol and gave an exemption from full review. Written informed consent was waived for this study because of the anonymous survey approach. This study followed the Checklist for Reporting Results of Internet E-Surveys (CHERRIES) (27).

\section{Survey Questionnaire}

The questionnaire, which accessed the knowledge level of PDDIs, was created based on previous studies and clinical practices in China $(22,24,28)$. This questionnaire has been reviewed by an expert panel that consisted of physician, pharmacists, outcomes researcher. The questionnaire included three sections; the first section was to ask physician's characteristics, including age, gender, education, years of practice, and specialty. The second section was to access physician's knowledge for PDDIs. Participants were asked to classify the 20-drug pairs into four categories: "no interaction" $(n=5)$, "have interaction, may be used together but with monitoring" ( $n=8)$, "contraindication" $(n=7)$, and "not sure." Each correct answer was given one point, with a maximum score of 20. These DDI pairs are commonly used in the literature testing the knowledge level of PDDIs $(22,24,28)$. We selected these drug pairs because they are frequently used in China with significant clinical impacts. The last section was to understand the source of information. As various sources of drug information may be used to check for PDDIs, the participants were expected to choose multiple answers from the options given. We also evaluated physician's altitude on the prevention of PDDIs. The 5-point Likert scale was used to allow the participants to express the extent they agree or disagree with the four statements regarding their altitude toward of avoiding PDDIs in practice. The questionnaire was shown in the Appendix.

\section{Participants Recruitment}

To reach a representative sample of physicians, following the previous research (29), we first selected 20 clinical pharmacists as the original delivers who invited the physicians in their units to participate. Physicians working in both community clinics and hospitals were invited to participate. Then we sent out private messages via WeChat that included a link to web-based questionnaire through an internet survey portal (https://www. 
wjx.cn/). WeChat is the largest social media platform in China and has been widely used to distribute online surveys $(30,31)$. Each WeChat account was allowed to answer the questionnaire once to avoid multiple response from the same participants. A total of 900 participants were invited in this survey and 709 physicians participated the survey. The response rate was $78.8 \%$.

The returned questionnaire was considered as eligible if [1] all the questions related to the PDDIs were answered; [2] the time spent on answering the questionnaire was within the range of 2-20 min, which was considered as typical timestamps. In the questionnaire development stage, we collected the feedbacks from a small group of physicians on whether the survey questions were clear. The typical timestamps were determined by the time they spent on completing the questionnaire. This approach has been applied in previous studies $(30,32)$. If the respondents submitted the same answers for all the PDDIs questions, then the questionnaire was excluded from the analysis.

\section{Data Analysis}

For descriptive analysis, frequency distributions (e.g., percentage) was used to describe categorical variables and means were used to describe continuous variables, respectively. Fisher's exact test was for categorical variables and Student's $t$-test was used for continuous variables. The mean was calculated to describe the score of PDDI questions. We also constructed an ordinary least square regression model to examine the potential predictors of PDDI knowledge, including physician's demographics, specialty, type of hospitals, practices, and their altitude toward PDDIs. The selection of these factors was based on the practices in China. The number of drug pairs categorized correctly was used as dependent variable, and the physician's self-reported characteristics and altitude on the PDDIs were included as independent variables. On the basis of parsimony, the interaction terms were not included in the regression model because the interacting effect of independent variables is difficult to interpret (22). Statistical significance was determined at a-level of 0.05. All statistical analyses were performed using SAS 9.4.

\section{RESULTS}

\section{Characteristics of Respondents}

After discarding 88 questionnaires that deemed ineligible based on predefined criteria, 618 (or 88\%) of 706 questionnaires were included in the analysis. As shown in Table 1, the majority (42.6\%) of respondents were aged between 30 and 39 years old; $353(57.1 \%)$ were female, and $256(41.4 \%)$ held a graduate degree. Most of physicians worked in community hospitals (38.8\%) and tertiary hospitals (38.8\%), and 25.9. 18.8, 35.1, and $14.6 \%$ of the respondents having practiced for $<5$ years, 5-9 years, 10-19 years, and more than 20 years, respectively. $40.0 \%$ of the respondents were internal medicine or family medicine physicians.

\section{Knowledge of PDDls}

Table 2 presents the frequencies (percentages) of respondents choosing each answer of the 20-drug pairs. On average, the respondents classified correctly 6.7 out of 20 pairs, or $33.4 \%$ of the drug interactions investigated. The number of drug
TABLE 1 | Self-reported characteristics of physicians who participated in the survey $(n=618)$.

\begin{tabular}{|c|c|c|}
\hline Characteristics & Number of participants $(n)$ & Percentage (\%) \\
\hline \multicolumn{3}{|l|}{ AGE } \\
\hline 20-29 & 127 & 20.6 \\
\hline 30-39 & 263 & 42.6 \\
\hline $40-19$ & 171 & 27.7 \\
\hline $50+$ & 57 & 9.2 \\
\hline \multicolumn{3}{|l|}{ GENDER } \\
\hline Male & 265 & 42.9 \\
\hline Female & 353 & 57.1 \\
\hline \multicolumn{3}{|l|}{ EDUCATION } \\
\hline High school & 1 & 0.2 \\
\hline College/Bachelor degree & 361 & 58.4 \\
\hline Graduate/Master degree & 256 & 41.4 \\
\hline \multicolumn{3}{|l|}{ TYPE OF HOSPITAL } \\
\hline Community hospital & 240 & 38.8 \\
\hline Secondary hospital & 66 & 10.7 \\
\hline Tertiary hospital & 240 & 38.8 \\
\hline Private hospital/others & 72 & 11.7 \\
\hline \multicolumn{3}{|l|}{ YEARS OF PRACTICE } \\
\hline$<5$ & 160 & 25.9 \\
\hline $5-9$ & 116 & 18.8 \\
\hline $10-19$ & 217 & 35.1 \\
\hline $20-30$ & 90 & 14.6 \\
\hline$>30$ & 35 & 5.7 \\
\hline \multicolumn{3}{|l|}{ SPECIALTY } \\
\hline Internal/general medicine & 247 & 40.0 \\
\hline Surgery & 92 & 14.9 \\
\hline Emergency medicine & 44 & 7.1 \\
\hline Others & 235 & 38.0 \\
\hline
\end{tabular}

pairs recognized by respondents was ranged from zero to 16 . The percentage of physicians who recognized specific drug pairs ranged from $8.3 \%$ for no interactions between conjugated estrogens and raloxifene, to $64.0 \%$ for the interaction between dopamine and phenytoin.

For the five drug combinations without interactions, $9.8 \%$ of the respondents answered correctly. For the 15 drug combinations that were considered as having interactions, which include both "contraindication" and "have interaction but may be used together with monitoring," $41.2 \%$ of them were categorized correctly by the respondents. Of particular, $15.1 \%$ of respondents categorized correctly for the six drug pairs having contradicted interactions, while $60.2 \%$ of the respondents categorized them as "needs to have close monitoring." For the seven drug pairs that were deemed with clinical significance by the expert panel (33), the majority of respondents detected the interactions, but $10 \%$ of the respondents still categorized as "no interaction" and 15\% of them answered "not sure."

\section{Source of PDDI Information}

The respondents' source of PDDI information was shown in Figure 1. When the respondents wanted to check PDDI information, the most commonly used source of information 
TABLE 2 | Frequencies (percentages) of physician's response to PDDIs ${ }^{a}$.

\begin{tabular}{|c|c|c|c|c|}
\hline Drug pairs & No interaction & May be used together but with monitoring & Contraindication & Not sure \\
\hline Acetaminophen/codeine and amoxicillin & $124(20.1 \%)$ & $337(54.5 \%)$ & $28(4.5 \%)$ & $129(20.9 \%)$ \\
\hline Warfarin and sulfamethoxazole/trimethoprim & $44(7.1 \%)$ & $376(60.8 \%)$ & 104 (16.8\%) & $94(15.2 \%)$ \\
\hline Warfarin and digoxin & $79(12.8 \%)$ & $377(61.0 \%)$ & $77(12.5 \%)$ & $85(13.8 \%)$ \\
\hline Digoxin and amiodarone & $26(4.2 \%)$ & $334(54.0 \%)$ & 185 (29.9\%) & $73(11.8 \%)$ \\
\hline Cyclosporine and rifampicin* & $48(7.8 \%)$ & $381(61.6 \%)$ & $108(17.5 \%)$ & $82(13.2 \%)$ \\
\hline Digoxin and itraconazole & $56(9.1 \%)$ & $390(63.1 \%)$ & $94(15.2 \%)$ & $78(12.6 \%)$ \\
\hline Digoxin and sildenafil & $53(8.6 \%)$ & $371(60.0 \%)$ & $114(18.5 \%)$ & $81(13.0 \%)$ \\
\hline Simvastatin and itraconazole & $62(10.0 \%)$ & $361(58.3 \%)$ & $113(18.3 \%)$ & $83(13.3 \%)$ \\
\hline Sildenafil and isosorbide mononitrate* & $47(7.6 \%)$ & $373(60.3 \%)$ & $102(16.5 \%)$ & $97(15.6 \%)$ \\
\hline Conjugated estrogens and raloxifene & $51(8.3 \%)$ & $387(62.6 \%)$ & 79 (12.8\%) & $101(16.3 \%)$ \\
\hline Theophylline and ciprofloxacin* & $83(13.4 \%)$ & $357(57.8 \%)$ & $75(12.1 \%)$ & $103(16.7 \%)$ \\
\hline Pimozide and ketoconazole* & $70(11.3 \%)$ & $366(59.1 \%)$ & $73(11.8 \%)$ & $110(17.7 \%)$ \\
\hline Warfarin and fluconazole & $59(9.6 \%)$ & $384(62.1 \%)$ & $82(13.3 \%)$ & $93(15.0 \%)$ \\
\hline Alprazolam and itraconazole* & 87 (14.1\%) & $373(60.4 \%)$ & $65(10.5 \%)$ & $93(15.0 \%)$ \\
\hline Digoxin and clarithromycin* & $73(11.8 \%)$ & $382(61.7 \%)$ & $52(8.4 \%)$ & $112(18.0 \%)$ \\
\hline Warfarin and sulfinpyrazone* & $50(8.1 \%)$ & $383(61.9 \%)$ & $101(16.3 \%)$ & $85(13.7 \%)$ \\
\hline Dopamine and phenytoin & $40(6.5 \%)$ & $396(64.0 \%)$ & 95 (15.4\%) & $88(14.2 \%)$ \\
\hline Fexofenadine and metoprolol & $58(9.4 \%)$ & 396 (64.0\%) & $62(10.0 \%)$ & $103(16.6 \%)$ \\
\hline Itraconazole and quinidine & $40(6.5 \%)$ & $382(61.7 \%)$ & $100(16.2 \%)$ & $97(15.6 \%)$ \\
\hline
\end{tabular}

a Bold text indicates the correct answers based on the Lexi-Interact.

*Indicates that these drug pairs were considered as clinically significant.

was package inserts $(n=572,92.6 \%)$. The less commonly used information sources were Internet or mobile Apps $(n=424$, $68.6 \%)$, consultation with clinical pharmacists $(n=384,62.1 \%)$, medical textbooks $(n=374,60.5 \%)$, knowledge base in Chinese $(n=283,45.8 \%)$, and consultation with other physicians $(n=$ $366,59.2 \%)$.

\section{Altitude Toward PDDIs}

As shown in Figure 2, 88.0\% of respondents reported that they always checked PDDIs while prescribing for patients, among them, $28.6 \%$ agreed with the statements and $59.4 \%$ strongly agreed, respectively. $69.1 \%$ of respondents agreed that they would consider PDDIs while prescribing. Less than half of the respondents agreed that the PDDI information were useful for their practice, but $78.0 \%$ of them had the willingness to improve their knowledge for PDDIs.

\section{Predictors of PDDI Knowledge}

In the multiple regression analysis, it revealed that significant predictors of a higher number of recognized drug pairs were years of practice $(p=0.015)$ and altitudes toward PDDIs (Table 3). Respondents who reported to check references for PDDIs detected more drug interactions than those who did not look for PDDIs $(p=0.029)$. Respondents who reported to consider PDDIs while prescribing for patients had lower score for PDDIs than those who did not $(p=0.011)$.

\section{DISCUSSION}

In this online survey accessing physician's ability to recognize PDDIs, less than half of the interacting drug combinations were recognized by the physicians who responded to the survey, which is consistent with previous studies conducted in the U.S. (22) and Central Saudi Arabia (28). Based on the participants' response, it seems that some potentially harmful drug interactions may not be detected by many physicians. For the seven drug combinations that are considered as contradicted, nearly $80 \%$ of the respondents categorized incorrectly. This insufficient detection of contradicted drug combinations could be partly explained by that the use of these drugs requires close monitoring, and hence a large proportion (around $60 \%$ ) of respondents chose "use with monitoring" rather than "contradicted." However, up to $25 \%$ of the physicians still remained unsure or unaware of these serious PDDIs. In addition, the participants were asked to restrict the use of references, which may contribute the relatively poor performance of recognizing PDDIs $(22,34)$.

Our findings also revealed that package inserts were the most commonly used information source for physicians when they need to check PDDIs, which is a major risk factor for incorrect medication use (26). As the electric databases or computerized systems are not widely available in China, it would be difficult for physicians to stay current with the best available evidence. With the busy working schedule, it appears to be impossible for physicians to check package inserts for every potential drug interaction they found, leading to substantial threats to the patient safety. Therefore, easily accessed scientific resources should be available for physicians to improve drug safety. Even with the assistance of the computerized systems to detect PDDIs, preventing DDIs is still difficult especially when more drugs are a part of a patient's daily schedule (35). Pharmacists and physicians tend to be desensitized to the alerts that are given by the software 


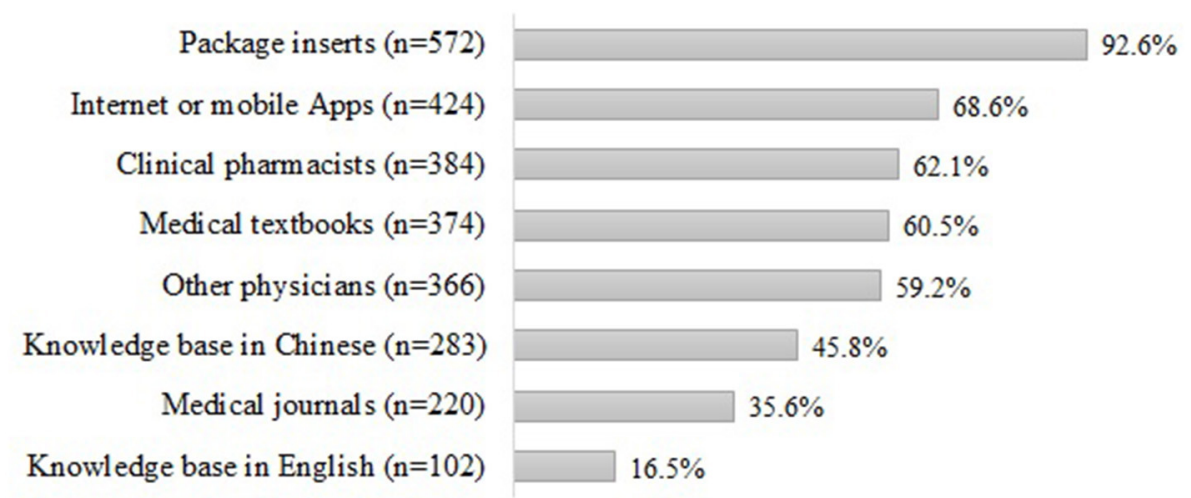

FIGURE 1 | Source of information for PDDIs ${ }^{a}$. a Sum may not be 100\% because respondents were allowed to choose multiple answers.

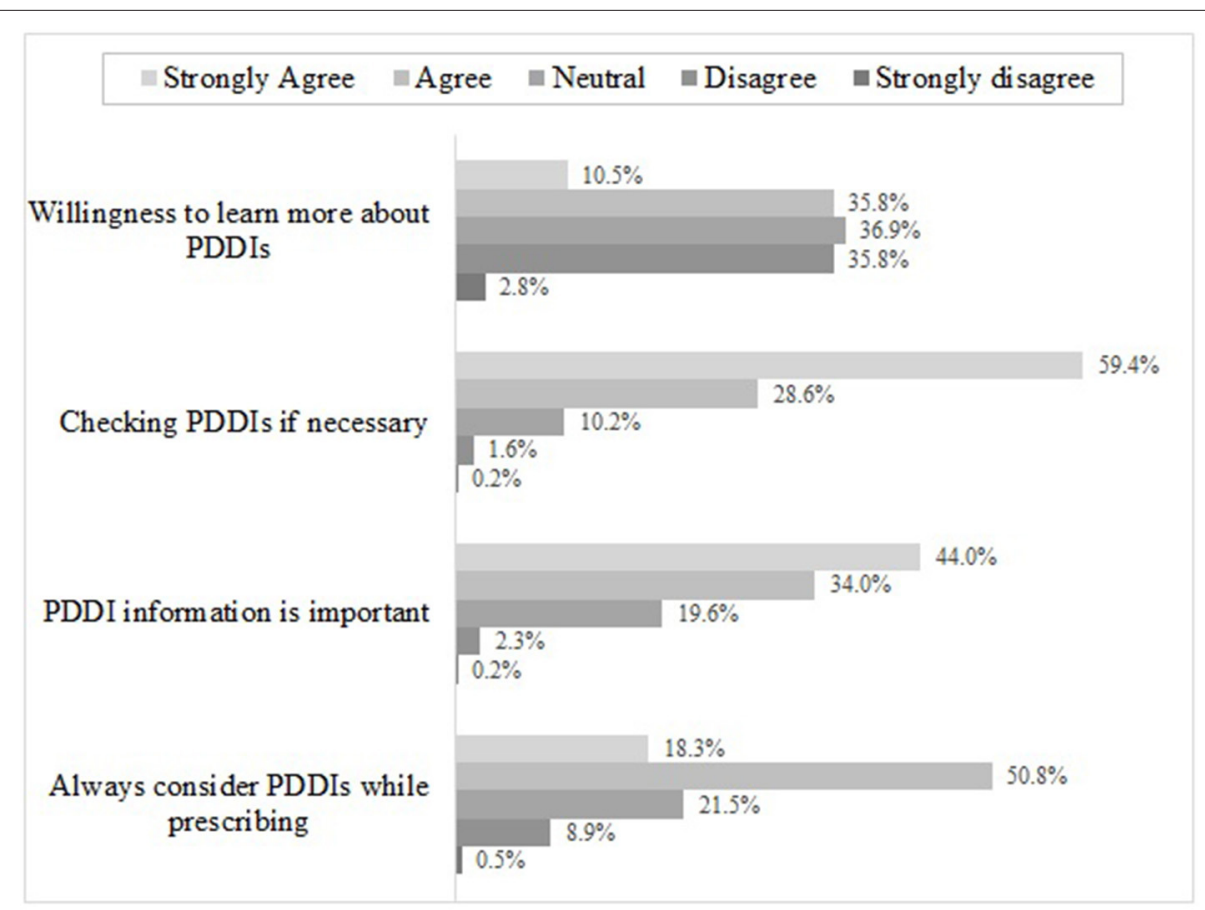

FIGURE 2 | Physician's altitude toward PDDIs*. *Sum may not be 100\% because respondents were allowed to choose multiple answers.

systems (36), mainly because they are given the option to override those alerts with mild or insignificant clinical outcomes $(35,36)$. Overriding alerts may become a habit for many pharmacists; in some clinical settings, the override rates could be as high as $71.9 \%$, which may rise the tendency of a pharmacist or physician to override a harmful PDDI (37). Hence, the burning issue of drug interaction won't be easily fixed by the implementation of the computerized system, a multi-facetted approach is necessary to improve drug safety.

This study also attempted to investigate the predictors of physician's PDDI knowledge. Due to small sample size, few predictors, including years of practice, type of hospital, and altitude toward PDDIs, were statistically significant. Higher scores for PDDIs were reported among physicians working in the secondary hospitals, potentially because they tend to provide care to a wide spectrum of non-surgical conditions and might be more familiar with the PDDIs included in the questionnaire. Noticeably, our analyses indicated the strong association between self-reported willingness to check references and knowledge of PDDIs as demonstrated by correct responses to drug pairs. Our finding highlighted the importance of raising awareness of PDDIs among physicians, possibly through continuing education with a specific focus on the most harmful PDDIs. Furthermore, twothirds of physicians would consult with pharmacists if they have question regarding PDDIs. Recently, the pharmacist's role in improving patient care has been recognized in China. For 
TABLE 3 | Predictors of the knowledge level for PDDIs ${ }^{\mathrm{a}}$.

\begin{tabular}{|c|c|c|c|}
\hline Characteristics & Estimate & Standard Error & $p$ \\
\hline \multicolumn{4}{|l|}{ AGE } \\
\hline 20-29 years & Ref & - & - \\
\hline 30-39 years & -0.04 & 0.25 & 0.875 \\
\hline 40-19 years & -0.53 & 0.33 & 0.111 \\
\hline $50+$ years & 1.44 & 0.51 & $0.005^{\star}$ \\
\hline \multicolumn{4}{|l|}{ GENDER } \\
\hline Male & Ref & - & - \\
\hline Female & 0.14 & 0.16 & 0.368 \\
\hline \multicolumn{4}{|l|}{ EDUCATION } \\
\hline High school & -2.96 & 1.84 & 0.108 \\
\hline College/Bachelor degree & 0.22 & 0.18 & 0.242 \\
\hline Graduate/Master degree & Ref & - & - \\
\hline \multicolumn{4}{|l|}{ YEARS OF PRACTICE } \\
\hline$<5$ years & Ref & - & - \\
\hline $5-9$ years & -0.29 & 0.25 & 0.261 \\
\hline $10-19$ years & 0.12 & 0.27 & 0.670 \\
\hline 20-30 years & 0.56 & 0.38 & 0.138 \\
\hline$>30$ years & 1.40 & 0.57 & $0.015^{\star}$ \\
\hline \multicolumn{4}{|l|}{ TYPE OF HOSPITAL } \\
\hline Community hospital & Ref & - & - \\
\hline Secondary hospital & 0.55 & 0.26 & $0.035^{\star}$ \\
\hline Tertiary hospital & 0.18 & 0.21 & 0.389 \\
\hline Private hospital/others & -0.28 & 0.27 & 0.298 \\
\hline \multicolumn{4}{|l|}{ SPECIALTY } \\
\hline Internal/general medicine & Ref & - & - \\
\hline Surgery & -0.33 & 0.24 & 0.162 \\
\hline Emergency medicine & -0.36 & 0.31 & 0.245 \\
\hline Others & -0.15 & 0.17 & 0.397 \\
\hline \multicolumn{4}{|l|}{ ALTITUDE } \\
\hline Always consider PDDIs while prescribing & -0.24 & 0.10 & $0.011^{*}$ \\
\hline Willingness to learn PDDls & 0.12 & 0.08 & 0.147 \\
\hline Considering PDDI as useful & -0.14 & 0.11 & 0.200 \\
\hline Looking for PDDI information & 0.26 & 0.12 & $0.029 *$ \\
\hline
\end{tabular}

${ }^{a}$ Predictors were estimated from the an ordinary least square regression. ${ }^{*} p<0.05$

example, the review of prescription by clinical pharmacists was mandated in tertiary hospitals in Shanghai. The physicianpharmacist collaboration model, in which pharmacists are included in the multidisciplinary heath care team, has been piloted in some tertiary hospitals. Most of PDDIs are preventable through quick response and effective team collaborations, therefore, more efforts should be pioneered in building up the physician-pharmacist collaboration to improve pharmaceutical care (7).

There are several limitations in this analysis. First, our findings have limited generalizability and may not reflect the general doctor population in terms of their level of knowledge about PDDIs. Despite of the efforts in the distribution of questionnaire, only a small proportion of physicians in China responded. Hence, the findings cannot be generalizable to all Chinese physicians.
Second, selection bias may exist because physicians who were familiar with PDDIs were more likely to participate the survey. As such, it will be impossible to understand the knowledge level of those physicians who did not participate the survey. Third, the questionnaire used to test the knowledge level of PDDIs is not validated, even though it was developed based on the existing studies $(22,24,28)$. The 20 -drug pairs might not be adequate to reflect the extent of knowledge applicable to the huge number of PDDIs. Hence, the physician's knowledge about PDDIs may not be well-accessed in this study. However, these DDI pairs have significant clinical impacts and every practicing physicians should be familiar with them. Last, we only included a couple of predictors for PDDI knowledge level, the lacking of confounders may cause inaccurate results of the multivariate regression model.

In conclusion, this study indicates unsatisfactory knowledge level about clinically significant drug interactions among physicians. This study also provides insights into where the physicians obtain their drug information. Continuing education and accessible electronic database can help physicians detecting PDDIs and improve drug safety.

\section{DATA AVAILABILITY STATEMENT}

The raw data supporting the conclusions of this article will be made available by the authors, without undue reservation.

\section{ETHICS STATEMENT}

The studies involving human participants were reviewed and approved by The Institutional Review Boards of Minhang Hospital of Fudan University. Written informed consent for participation was not required for this study in accordance with the national legislation and the institutional requirements.

\section{AUTHOR CONTRIBUTIONS}

JY and CS: concept and design. CS, BH, CW, and GS: acquisition, analysis, or interpretation of data. CS and JY: drafting of the manuscript. JY, GS, BH, CW, and CS: critical revision of the manuscript for important intellectual content. JY: statistical analysis. JY and $\mathrm{BH}$ : administrative, technical, or material support and supervision. All authors approved the final manuscript as submitted and agree to be accountable for all aspects of the work.

\section{ACKNOWLEDGMENTS}

The authors are very grateful to physicians who participated in the survey.

\section{SUPPLEMENTARY MATERIAL}

The Supplementary Material for this article can be found online at: https://www.frontiersin.org/articles/10.3389/fmed. 2021.650369/full\#supplementary-material 


\section{REFERENCES}

1. Zheng WY, Richardson LC, Li L, Day RO, Westbrook JI, Baysari MT. Drug-drug interactions and their harmful effects in hospitalised patients: a systematic review and meta-analysis. Eur J Clin Pharmacol. (2018) 74:1527. doi: 10.1007/s00228-017-2357-5

2. Dechanont S, Maphanta S, Butthum B, Kongkaew C. Hospital admissions/visits associated with drug-drug interactions: a systematic review and meta-analysis. Pharmacoepidemiol Drug Saf. (2014) 23:489-97. doi: 10.1002/pds.3592

3. Askari M, Eslami S, Louws M, Wierenga PC, Dongelmans DA, Kuiper RA, et al. Frequency and nature of drug-drug interactions in the intensive care unit. Pharmacoepidemiol Drug Saf. (2013) 22:430-7. doi: 10.1002/pds.3415

4. Juurlink DN, Mamdani M, Kopp A, Laupacis A, Redelmeier DA. Drug-drug interactions among elderly patients hospitalized for drug toxicity. JAMA. (2003) 289:1652-8. doi: 10.1001/jama.289.13.1652

5. Kelly CM, Juurlink DN, Gomes T, Duong-Hua M, Pritchard KI, Austin PC, et al. Selective serotonin reuptake inhibitors and breast cancer mortality in women receiving tamoxifen: a population based cohort study. BMJ. (2010) 340:c693. doi: 10.1136/bmj.c693

6. Ren W, Liu Y, Zhang J, Fang Z, Fang H, Gong Y, et al. Prevalence of potential drug-drug interactions in outpatients of a general hospital in China: a retrospective investigation. Int J Clin Pharm. (2020) 42:11906. doi: 10.1007/s11096-020-01068-3

7. Hwang AY, Gums TH, Gums JG. The benefits of physician-pharmacist collaboration. J Fam Pract. (2017) 66:E1-8.

8. Ismail M, Khan F, Noor S, Haider I, Haq IU, Ali Z, et al. Potential drugdrug interactions in medical intensive care unit of a tertiary care hospital in Pakistan. Int J Clin Pharm. (2016) 38:1052-6. doi: 10.1007/s11096-016-0340-3

9. Fernández de Palencia Espinosa M, Díaz Carrasco MS, Sánchez Salinas A, de la Rubia Nieto A, Miró AE. Potential drug-drug interactions in hospitalised haematological patients. J Oncol Pharm Pract. (2017) 23:44353. doi: $10.1177 / 1078155216664201$

10. Ribed A, Romero-Jiménez RM, Escudero-Vilaplana V, Iglesias-Peinado I, Herranz-Alonso A, Codina C, et al. Pharmaceutical care program for oncohematologic outpatients: safety, efficiency and patient satisfaction. Int J Clin Pharm. (2016) 38:280-8. doi: 10.1007/s11096-015-0235-8

11. Moura CS, Acurcio FA, Belo NO. Drug-drug interactions associated with length of stay and cost of hospitalization. J Pharm Pharm Sci. (2009) 12:26672. doi: $10.18433 / \mathrm{J} 35 \mathrm{C} 7 \mathrm{Z}$

12. Shad MU, Marsh C, Preskorn SH. The economic consequences of a drug-drug interaction. J Clin Psychopharmacol. (2001) 21:119-20. doi: 10.1097/00004714-200102000-00027

13. Moura C, Prado N, Acurcio F. Potential drug-drug interactions associated with prolonged stays in the intensive care unit: a retrospective cohort study. Clin Drug Investig. (2011) 31:309-16. doi: 10.1007/BF03256929

14. Carpenter M, Berry H, Pelletier AL. Clinically relevant drug-drug interactions in primary care. Am Fam Physician. (2019) 99:558-64.

15. Abarca J, Colon LR, Wang VS, Malone DC, Murphy JE, Armstrong EP. Evaluation of the performance of drug-drug interaction screening software in community and hospital pharmacies. J Manag Care Pharm. (2006) 12:3839. doi: $10.18553 /$ jmcp.2006.12.5.383

16. Blix HS, Viktil KK, Moger TA, Reikvam A. Identification of drug interactions in hospitals-computerized screening vs. bedside recording. J Clin Pharm Ther. (2008) 33:131-9. doi: 10.1111/j.1365-2710.2007.00893.x

17. Roblek T, Vaupotic T, Mrhar A, Lainscak M. Drug-drug interaction software in clinical practice: a systematic review. Eur J Clin Pharmacol. (2015) 71:13142. doi: 10.1007/s00228-014-1786-7

18. Fung KW, Kapusnik-Uner J, Cunningham J, Higby-Baker S, Bodenreider O. Comparison of three commercial knowledge bases for detection of drugdrug interactions in clinical decision support. J Am Med Inform Assoc. (2017) 24:806-12. doi: 10.1093/jamia/ocx010

19. Weingart SN, Simchowitz B, Shiman L, Brouillard D, Cyrulik A, Davis RB, et al. Clinicians' assessments of electronic medication safety alerts in ambulatory care. Arch Intern Med. (2009) 169:1627-32. doi: 10.1001/archinternmed.2009.300

20. Saverno KR, Hines LE, Warholak TL, Grizzle AJ, Babits L, Clark C, et al. Ability of pharmacy clinical decision-support software to alert users about clinically important drug-drug interactions. J Am Med Inform Assoc. (2011) 18:32-7. doi: 10.1136/jamia.2010.007609
21. Bates DW, Leape LL. Pharmacies and prevention of potentially fatal drug interactions-reply. JAMA. (1996) 275:1086-7. doi: 10.1001/jama.275. 14.1086

22. Ko Y, Malone DC, Skrepnek GH, Armstrong EP, Murphy JE, Abarca J, et al. Prescribers' knowledge of and sources of information for potential drug-drug interactions: a postal survey of US prescribers. Drug Saf. (2008) 31:525-36. doi: 10.2165/00002018-200831060-00007

23. Weideman RA, Bernstein IH, McKinney WP. Pharmacist recognition of potential drug interactions. Am J Health Syst Pharm. (1999) 56:15249. doi: 10.1093/ajhp/56.15.1524

24. Gilligan AM, Warholak TL, Murphy JE, Hines LE, Malone DC. Pharmacy students' retention of knowledge of drug-drug interactions. Am J Pharm Educ. (2011) 75:110. doi: 10.5688/ajpe756110

25. Glassman PA, Belperio P, Simon B, Lanto A, Lee M. Exposure to automated drug alerts over time: effects on clinicians' knowledge and perceptions. Med Care. (2006) 44:250-6. doi: 10.1097/01.mlr.0000199849.08389.91

26. Rational use of medicines. Lancet. (2010) 375:2052. doi: 10.1016/S0140-6736(10)60944-0

27. Eysenbach G. Improving the quality of Web surveys: the checklist for reporting results of internet e-surveys (CHERRIES). J Med Internet Res. (2004) 6:e34. doi: 10.2196/jmir.6.3.e34

28. Alrabiah Z, Alhossan A, Alghadeer SM, Wajid S, Babelghaith SD, AlArifi MN. Evaluation of community pharmacists' knowledge about drugdrug interaction in Central Saudi Arabia. Saudi Pharm J. (2019) 27:4636. doi: 10.1016/j.jsps.2019.01.008

29. Sun T, Gao L, Li F, Shi Y, Xie F, Wang J, et al. Workplace violence, psychological stress, sleep quality and subjective health in Chinese doctors: a large cross-sectional study. BMJ Open. (2017) 7:e017182. doi: 10.1136/bmjopen-2017-017182

30. Hua F, Qin D, Yan J, Zhao T, He H. COVID-19 related experience, knowledge, attitude, and behaviors among 2,669 orthodontists, orthodontic residents, and nurses in China: a cross-sectional survey. Front Med. (2020) 7:481. doi: $10.3389 /$ fmed.2020.00481

31. Xu H, Gonzalez Mendez MJ, Guo L, Chen Q, Zheng L, Chen P, et al. Knowledge, awareness, and attitudes relating to the COVID-19 pandemic among different populations in central china: cross-sectional survey. J Med Int Res. (2020) 22:e22628. doi: 10.2196/22628

32. Liu N, Zhang F, Wei C, Jia Y, Shang Z, Sun L, et al. Prevalence and predictors of PTSS during COVID-19 outbreak in China hardest-hit areas: Gender differences matter. Psychiatry Res. (2020) 287:112921. doi: 10.1016/j.psychres.2020.112921

33. Malone DC, Abarca J, Hansten PD, Grizzle AJ, Armstrong EP, Van Bergen $\mathrm{RC}$, et al. Identification of serious drug-drug interactions: results of the partnership to prevent drug-drug interactions. J Am Pharm Assoc. (2004) 44:142-51. doi: 10.1331/154434504773062591

34. Glassman PA, Simon B, Belperio P, Lanto A. Improving recognition of drug interactions: benefits and barriers to using automated drug alerts. Med Care. (2002) 40:1161-71. doi: 10.1097/00005650-200212000-00004

35. Bagri H, Dahri K, Legal M. Hospital pharmacists' perceptions and decisionmaking related to drug-drug interactions. Can J Hosp Pharm. (2019) 72:28894. doi: 10.4212/cjhp.v72i4.2915

36. Tannenbaum C, Sheehan NL. Understanding and preventing drug-drug and drug-gene interactions. Exp Rev Clin Pharmacol. (2014) 7:53344. doi: 10.1586/17512433.2014.910111

37. Bhakta SB, Colavecchia AC, Haines L, Varkey D, Garey KW. A systematic approach to optimize electronic health record medication alerts in a health system. Am J Health Syst Pharm. (2019) 76:530-6. doi: 10.1093/ajhp/ zxz012

Conflict of Interest: The authors declare that the research was conducted in the absence of any commercial or financial relationships that could be construed as a potential conflict of interest.

Copyright (ङ) 2021 Yuan, Shen, Wang, Shen and Han. This is an open-access article distributed under the terms of the Creative Commons Attribution License (CC BY). The use, distribution or reproduction in other forums is permitted, provided the original author(s) and the copyright owner(s) are credited and that the original publication in this journal is cited, in accordance with accepted academic practice. No use, distribution or reproduction is permitted which does not comply with these terms. 